\title{
Single-virus fusion measurements yield an opportunistic model for SARS-CoV-2 fusion
}

Anjali Sengar ${ }^{1}$, Sai T. Bondalapati ${ }^{1}$, and Peter M. Kasson ${ }^{1,2, *}$

1. Departments of Molecular Physiology and Biomedical Engineering, Global Infectious

Diseases Institute, University of Virginia, Charlottesville, Virginia 22908 USA

2. Department of Cell and Molecular Biology, Uppsala University, Uppsala 75123, Sweden.

*kasson@virginia.edu

\begin{abstract}
SARS-CoV-2 virus, like many coronaviruses, binds to cell-surface receptors and is then activated for membrane fusion and cell entry via proteolytic cleavage. In some coronaviruses, this occurs primarily at the cell surface, while in others primarily in endosomes. Prior data on SARS-CoV-2 suggest that either can happen, depending on cell type, and there has been debate regarding the physiologically relevant mechanism of entry. Here we use single-virus fusion experiments using isolated plasma membrane and exogenously controlled proteases to probe the question of protease activation directly. We find that a broad range of proteases can activate SARS-CoV-2 pseudoviruses for fusion, that this does not depend on the pseudovirus genetic background, and that the plasma membrane is competent to support fusion. Furthermore, protease activation can occur either prior or subsequent to receptor binding. The resulting data suggest a model of opportunistic fusion by SARS-CoV-2, where the subcellular location of entry depends on airway protease activity, cell-surface protease activity, and endosomal protease activity, but all can support infection. These parallel pathways help explain why targeted host protease inhibition has shown strong efficacy in cell-culture models but weaker efficacy in clinical trials.
\end{abstract}

\section{Introduction}

The SARS-CoV-2 betacoronavirus has spread globally since late 2019, causing over 150 million confirmed infections and over 3.2 million deaths. As with many coronaviruses, it binds to a cellsurface receptor and is activated for membrane fusion and cell entry by proteolytic cleavage of its spike protein by a host protease. The primary receptor for SARS-CoV-2 binding, as with SARSCoV binding, is ACE-2 ${ }^{1-5}$. This is a common, but not universal, binding receptor among betacoronaviruses infecting humans ${ }^{6}$; MERS-CoV utilizes DPP4 as a means of host-cell attachment ${ }^{7}$. However, the biochemical steps following viral attachment and their roles in cell entry and physiological infection have to date been somewhat less clear.

The host protease responsible for activation and the subsequent subcellular location of viral membrane fusion vary substantially among betacoronaviruses ${ }^{8}$. SARS-CoV appears to utilize cathepsins present in late endosomes for activation, entering via the endocytic pathway ${ }^{9-11}$, although in other cell types it can enter at the cell surface ${ }^{12-13}$. MERS-CoV is potently activated by TMPRSS ${ }^{14}$, permitting cell-surface entry, although it appears that it can also be activated by furin and potentially other proteases ${ }^{15-16}$. Initial data on SARS-CoV-2 have indicated the potential for each of these activation and entry mechanisms ${ }^{17-22}$, with some ensuing debate about the biochemical and physiological relevance of cell-surface versus endosomal entry and whether this depends on cell type. 
The site of host proteolytic cleavage limits how early a virus can undergo fusion and entry, but it does not by itself establish the site of entry. A second trigger may be required, as in the case of Ebola ${ }^{9,23-24}$, or the subcellular compartment where proteolysis occurs may not be permissive for entry. Targeted proteolytic inhibitors and inhibitors of intracellular trafficking provide information on the sites of entry ${ }^{5,25}$, but they also potentially perturb membrane composition. An alternative is to biochemically isolate subcellular compartments and exogenously trigger fusion ${ }^{26}$. This permits more biochemically precise and controlled testing of cellular requirements for viral entry.

Studying viral entry in reconstituted systems has yielded substantial insight into the biochemical requirements for entry, including the effects of membrane composition and receptor chemical structure $^{26-34}$. A virus-like membrane context does appear important to mechanism, however, as both coronavirus and influenza virus cell-cell fusion have well-described differences from viruscell fusion ${ }^{35-37}$. Single-virus assays have enabled an added level of mechanistic sophistication, as they permit analysis of heterogeneity among viral particles and straightforward estimates of

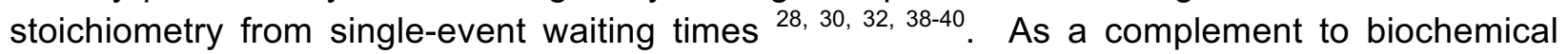
reconstitution, single-virus fusion studies on isolated cellular membranes held under exogenous control $^{26,28,41}$ permit both the control of reconstituted systems and the physiological membrane environment of cells. This is the approach reported here.

Here we report single-virus fusion studies of SARS-CoV-2 pseudovirions with isolated plasma membrane and controlled exogenous protease treatment. We show that SARS-CoV-2 spike protein can be activated for fusion by a diverse range of host proteases present in the extracellular environment, on the cell surface, and within endosomes. We also show that the plasma membrane is permissive for viral entry and that additional endosomal factors are not required. This supports an "opportunistic" model of SARS-CoV-2 entry, where protease activation can occur at several different stages of viral transport and can lead to fusion with whichever cellular membrane is present at the time.

\section{Results}

To measure single-virus fusion mediated by SARS-CoV-2 spike proteins, we used an approach previously developed for influenza and Zika virus ${ }^{40,42}$ and highly similar to related assays for HIV and coronavirus fusion ${ }^{28,41}$. Briefly (Fig. 1), target membranes-in this case host cell plasma membrane vesicles_are immobilized in a microfluidic flow cell. Virus is labeled with a lipid-phase dye at self-quenching concentration, protease-activated, added to the flow cell, and allowed to bind and fuse. Fusion is assessed via lipid mixing between the virus and the host-cell membranes, detected as fluorescence dequenching in optical microscopy. 
(a) SARS-CoV-2

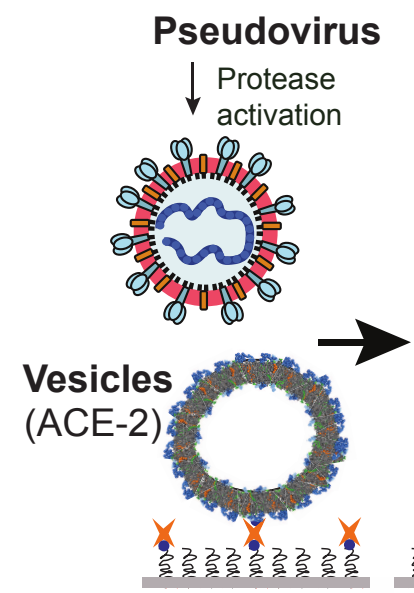

(I)

\section{Receptor Lipid Mixing} Q 0

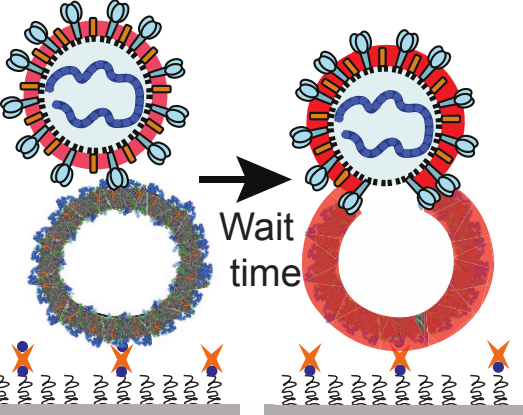

(II)

(III) (b)

(I)

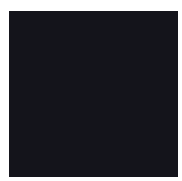

(c)

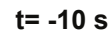

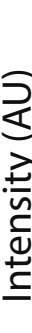

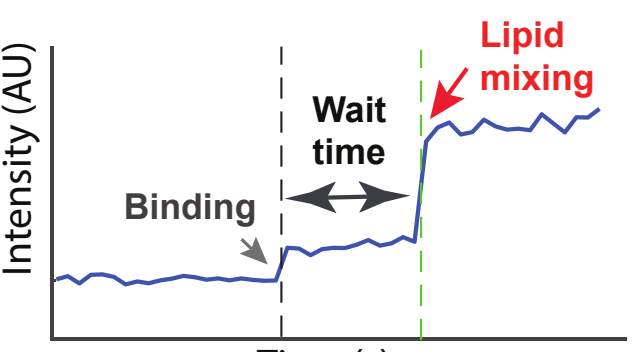

Time (s)
(II)

$\mathrm{t}=\mathbf{0} \mathrm{s}$

$t=30 s$

(III)

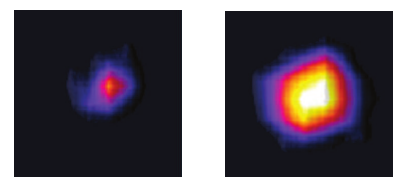

Lipid

Figure 1. Fusion of SARS-CoV-2 pseudoviruses to plasma membrane vesicles. Panel (a) schematizes the assay design, panel (b) shows fluorescence images corresponding to schematized stages (I-III), and panel (c) shows the corresponding fluorescence intensity trace. Texas Red-DHPE dye is loaded into pseudoviral membranes at a quenching concentration, and plasma membrane vesicles containing ACE-2 receptor are immobilized in a microfluidic flow cell (I). Virus-vesicle binding results in a fluorescent spot (II), and lipid mixing between virus and vesicle causes dye dequenching and a further increase in fluorescence (III). This permits measurement of individual pseudovirus fusion events.

In this case, we used three different pseudovirus systems. Pseudoviruses were expressed on HIV, VSV, and MLV backgrounds. All of these pseudoviruses infected Vero cells successfully (Fig. S1) but did not carry SARS-CoV-2 genomes and thus could not replicate. Host-cell plasma membranes were isolated by blebbing giant plasma-membrane vesicles from cultured cells ${ }^{43}$, biotinylating these membranes, and then immobilizing them in a flow cell using PLL-PEG-biotin and streptavidin as previously reported ${ }^{44}$. Because we observed proteolytic activation of SARSCoV-2 spike protein to be relatively slow, fusion assays were performed by pre-incubating viral particles with the protease of interest and then allowing the activated particles to bind. However, we also observed activation and fusion (albeit more slowly) without pre-incubation when membrane-bound proteases are present on the target membranes and proteolysis occurs subsequent to receptor-binding (Fig. S2).

For testing of exogenous proteases, Vero cell plasma membrane vesicles were used due to their low levels of TMPRSS2 expression yet good ACE-2 receptor expression. Indeed, minimal fusion was observed to Vero cell membranes in the absence of exogenous protease, while somewhat more fusion was observed to Calu-3 cell membranes with accompanying higher levels of TMPRSS2 expression (Fig. S2). 

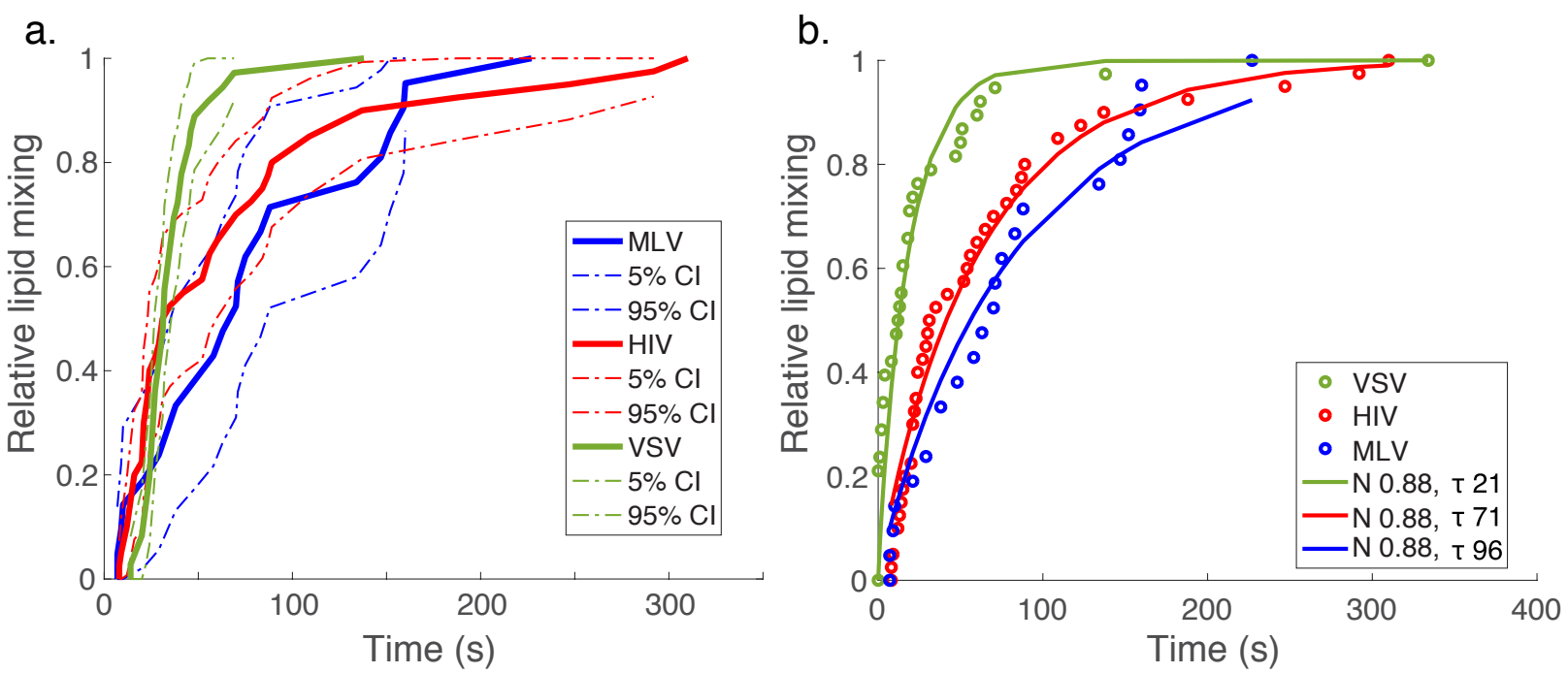

Figure 2. SARS-CoV-2 spike mediates fusion when expressed on different pseudoviral backgrounds. Cumulative distribution functions for single-virus fusion are plotted in panel (a) for SARS-CoV-2 spike protein expressed on VSV (green), HIV (red), and VSV (blue) genetic backgrounds and proteolytically activated using trypsin. All three result in productive fusion (lipid mixing shown here; evidence of downstream fusion shown in Fig. S1). Dashed lines show 90\% confidence intervals. Fusion with VSV pseudoviruses is slightly faster than with HIV or MLV pseudoviruses; we hypothesize these differences are due to greater SARS-CoV-2 spike density on the viral surface. Fits to these cumulative distribution functions are shown in panel (b) and Fig. S3.

Analysis of fusion kinetics by proteolytically activated pseudovirions is made challenging by the fact that proteolytic activation and binding are substantially slower than subsequent fusion. We corrected for this by taking virions pre-incubated with protease that then show distinct binding and fusion events on fluorescence microscopy (Fig. 1). These selection criteria may bias the kinetic analysis by not including viruses where binding and fusion occur within the same frame (<1s), but this provides a lower limit for fusion. Additional data on total fluorescence change from lipid mixing integrated across the $133 \times 133 \mu \mathrm{m}$ microscope field of view are given in the Supplement. Cumulative distribution functions were calculated for trypsin-activated fusion by SARS-CoV-2 spike protein on each of the three pseudovirus genetic backgrounds. These results (Fig. 2) show fastest fusion on a VSV background, slowest on an MLV background, with HIV-based pseudovirions intermediate. Single-virus waiting times were statistically different between VSV and either MLV or HIV ( $p=<0.001$ via 2-tailed Kolmogorov-Smirnov test with Bonferroni correction) but not between HIV and MLV backgrounds ( $p=0.69$, 2-tailed Kolmogorov-Smirnov test). The minimum number of kinetic steps in a linear pathway for fusion has previously been interpreted as the fusion protein stoichiometry in cases where fusion protein activation is ratelimiting for lipid mixing ${ }^{30,32,44-46}$. The apparent fusion protein stoichiometry for SARS-CoV-2 spike fusion is between 1 and 3: $\quad N_{\min }$ values were calculated at $0.89(95 \% \mathrm{Cl} 0.61-1.6)$ for $\mathrm{HIV}$ pseudoviruses, $1.8(95 \% \mathrm{Cl} 1.2-3.4)$ for MLV pseudoviruses, and 0.29 (95\% Cl 0.12-0.84) for VSV pseudoviruses. Interestingly, both HIV and VSV pseudoviruses show $N_{\min }$ values of less than 1. This has previously been discussed in the context of dynamic disorder ${ }^{38,47}$ or non-linear reaction pathways ${ }^{48-49}$. In this case, we hypothesize that the observations are due to static 
disorder, namely multiple populations of pseudovirus that have different fusion rates due to different spike protein densities (Fig. S4).

At a coarser level, we hypothesize that the maximum-likelihood stoichiometry is identical between viruses but that the rates of fusion vary across pseudovirus backgrounds, likely due to changes in spike density. We therefore fit cumulative distribution functions to a gamma-distribution model ${ }^{30}$, where the functional form is $f(t, N, \tau)=\frac{1}{\tau^{N} \Gamma(\mathrm{N})} \int_{0}^{t} t^{N-1} e^{-t / \tau} d t$, where $\Gamma(\mathrm{N})$ is a gamma function. We performed two sets of fits, either allowing all parameters to vary independently (Fig. S3) or constraining $N$ to be identical across pseudovirus backgrounds but allowing tau to vary (Fig. $2 \mathrm{~b}$ ). The results show high-quality fits with a constraint of common stoichiometry (RMSE $=0.08,0.03$, 0.06 for VSV, HIV, MLV respectively and Akaike Information Criterion (AIC) values of 2470 versus AIC of 2530 for unconstrained stoichiometry support the simpler model of a common stoichiometry), thus suggesting a single most-likely fusion protein stoichiometry. In combination with the single-turnover variance analysis $\left(N_{\min }\right)$ discussed above, we conclude that there is likely static disorder present in the sample i.e. different pseudoviruses have different spike protein arrangements on their surfaces but that the spike protein stoichiometry required for fusion likely does not vary between pseudovirus backgrounds. Instead, the static disorder manifests as different apparent fusion rates.

Fusion mediated by each SARS-CoV-2 spike-bearing pseudovirus was measured at multiple trypsin concentrations to assess differences in fusogenicity of these different constructs. Results show differences in fusion efficiency (Fig. S5, Fig. S6) with monotonic increases as a function of protease concentration until saturation is reached. Cumulative distribution functions calculated for HIV pseudovirions treated with $50 \mu \mathrm{g} / \mathrm{mL}$ and $100 \mu \mathrm{g} / \mathrm{mL}$ trypsin show similar fusion kinetics (Fig. 3a): the data are compatible with a model where the stoichiometry of fusion is identical, and the fusion rates are with error of each other. The single-particle waiting time distributions were not significantly different from each other ( $p>0.97$, 2-tailed Kolmogorov-Smirnov test). These data are again compatible with a similar activation stoichiometry across pseudovirus backgrounds, subject to heterogeneous populations as discussed above; this may however vary between virus-cell fusion and cell-cell fusion as has been suggested for influenza ${ }^{36}$. 
a.

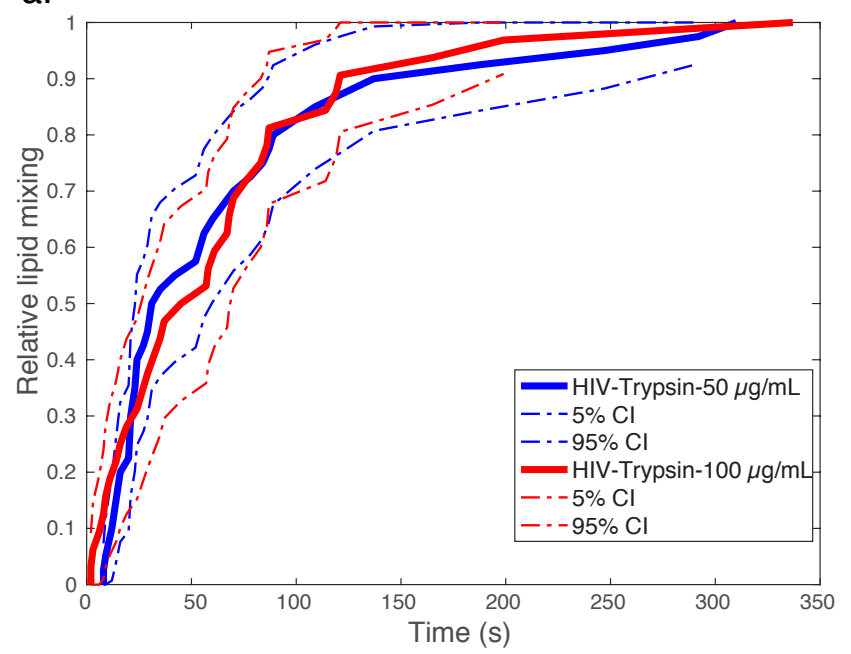

b.

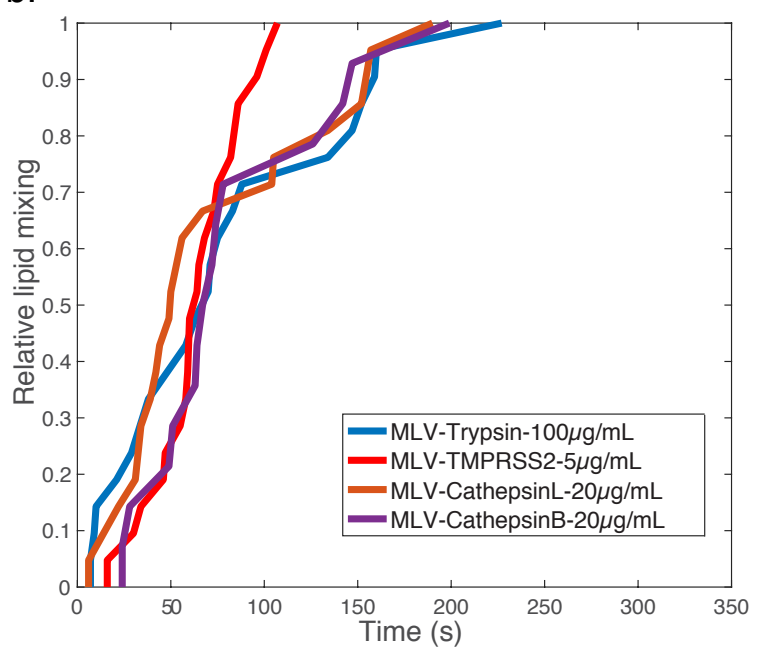

Figure 3. SARS-CoV-2 spike-mediated fusion shows indistinguishable kinetics across protease conditions. Plotted in panel (a) are cumulative distribution functions from single-virus lipid mixing when pseudoviruses were activated with 50 or $100 \mu \mathrm{g} / \mathrm{mL}$ trypsin. Dashed lines are $90 \%$ confidence intervals. Plotted in panel (b) are similar cumulative distribution functions with different exogenous proteases (confidence intervals omitted for visual clarity; two-tailed Kolmogorov-Smirnov tests show no significant differences ( $p>0.25)$.

Finally, we tested the ability of multiple trypsin-like proteases to activate SARS-CoV-2 pseudovirions for fusion. We tested each of the following proteases. Human airway trypsin-like protease (HAT), also known as TMPRSS11D, is a serine protease expressed in both lower and upper airway tissues, found in sputum, and also expressed in other tissues ${ }^{50-52}$. HAT has previously been suggested as a candidate for SARS-CoV-2 proteolytic activation ${ }^{21}$. Cathepsins $B$ and $L$ are late-endosomal proteases implicated in activation of other viruses including SARSCoV ${ }^{10-11,17,53}$. Finally, TMPRSS2 is a cell-surface protease expressed in type 2 alveolar cells among others that has been implicated in MERS proteolytic activation and is a primary candidate for SARS-CoV-2 proteolytic activation ${ }^{5,18}$. Each of these was indeed capable of activating SARSCoV-2 spike protein for fusion (Fig. 3b; Fig. S6; Fig. S7). None of the single-particle waiting time distributions were significantly different from each other $(p>0.25$, 2-tailed Kolmogorov-Smirnov test), although TMPRSS2 shows slightly but not significantly faster fusion.

\section{Discussion and Conclusions}

Based on these data, we propose an opportunistic model of SARS-CoV-2 activation and entry. Proteolytic activation by cleavage at the S2' site can occur in the airway extracellular milieu, at the cell surface, or within late endosomes. Furthermore, proteolytic activation can either precede or follow receptor binding; these events need not occur in sequence. We also demonstrate that the plasma membrane is capable of supporting SARS-CoV-2 fusion in addition to endosomes. We therefore propose a model (Fig. 4) where the site of SARS-CoV-2 entry is stochastically determined based on the proteases present in a given tissue and the rates of spike protein cleavage relative to the rates of viral attachment and endocytosis. In cases where extracellular or cell-surface proteolysis is rapid, entry will tend to occur at the cell surface, whereas if extracellular and cell-surface proteolysis are slow, entry will tend to occur within endosomes. This 
opportunistic entry and ability to utilize parallel pathways may help explain why protease inhibitors such as camostat mesylate are effective in cell and tissue models but show less efficacy in clinical trials $^{5,54-56}$.

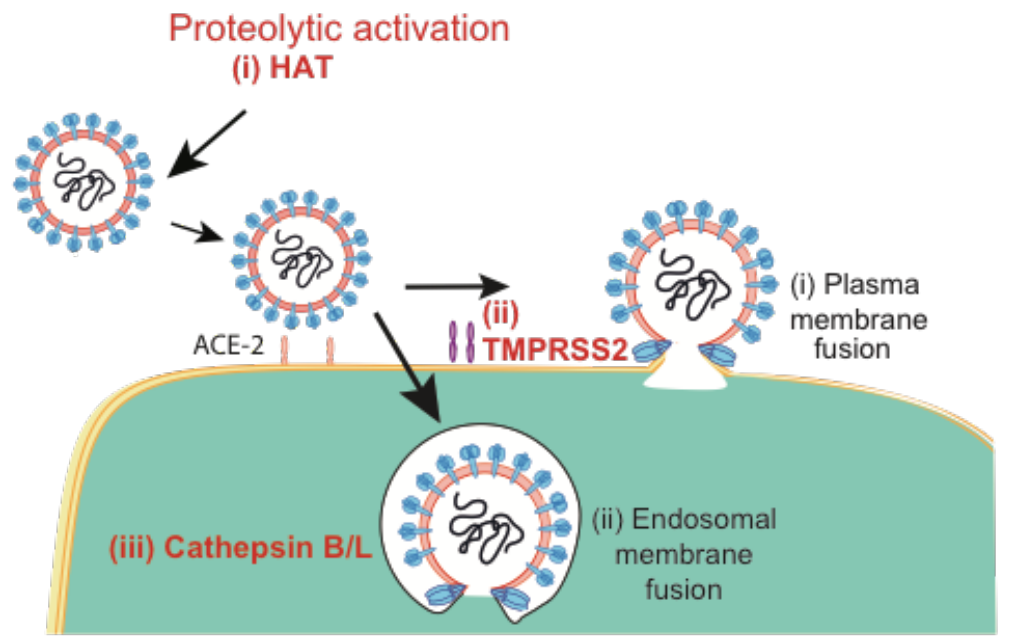

Figure 4. Opportunistic activation and entry of SARS-CoV-2. We propose a model where SARS-CoV-2 undergoes proteolytic activation prior to membrane fusion but where this activation can occur (i) in the extracellular fluid prior to binding, (ii) at the cell surface after binding, or (iii) within endosomes. Both (i) plasma membrane and (ii) endosomal membranes are permissive for viral entry. Thus viral entry requires activation and binding to a host membrane, but the requirements for these two are loose rather than stringent.

\section{Acknowledgements}

The authors thank Jesse Bloom, Benhur Lee, and Judith White for the gift of reagents and M. Cervantes, G. Morbioli, A. Villamil Giraldo, R. Rawle, and J. White for helpful discussions. Electron cryo-microscopy was performed by K. Dryden at the Molecular Electron Microscopy Core at the University of Virginia. This work was supported by grants from the Commonwealth Health Research Board, the UVA Global Infectious Diseases Institute, and a Wallenberg Academy Fellowship to P.M.K.

\section{References}

1. Nie, Y.; Wang, P.; Shi, X.; Wang, G.; Chen, J.; Zheng, A.; Wang, W.; Wang, Z.; Qu, X.; Luo, M.; Tan, L.; Song, X.; Yin, X.; Chen, J.; Ding, M.; Deng, H., Highly infectious SARS-CoV pseudotyped virus reveals the cell tropism and its correlation with receptor expression. Biochem Biophys Res Commun 2004, 321 (4), 994-1000.

2. Zhou, P.; Yang, X. L.; Wang, X. G.; Hu, B.; Zhang, L.; Zhang, W.; Si, H. R.; Zhu, Y.; Li, B.; Huang, C. L.; Chen, H. D.; Chen, J.; Luo, Y.; Guo, H.; Jiang, R. D.; Liu, M. Q.; Chen, Y.; Shen, X. R.; Wang, X.; Zheng, X. S.; Zhao, K.; Chen, Q. J.; Deng, F.; Liu, L. L.; Yan, B.; Zhan, F. X.; Wang, Y. Y.; Xiao, G. F.; Shi, Z. L., A pneumonia outbreak associated with a new coronavirus of probable bat origin. Nature 2020, 579 (7798), 270-273.

3. Yan, R.; Zhang, Y.; Li, Y.; Xia, L.; Guo, Y.; Zhou, Q., Structural basis for the recognition of SARS-CoV-2 by full-length human ACE2. Science 2020, 367 (6485), 1444-1448. 
4. Shang, J.; Ye, G.; Shi, K.; Wan, Y.; Luo, C.; Aihara, H.; Geng, Q.; Auerbach, A.; Li, F., Structural basis of receptor recognition by SARS-CoV-2. Nature 2020.

5. Hoffmann, M.; Kleine-Weber, H.; Schroeder, S.; Kruger, N.; Herrler, T.; Erichsen, S.; Schiergens, T. S.; Herrler, G.; Wu, N. H.; Nitsche, A.; Muller, M. A.; Drosten, C.; Pohlmann, S., SARS-CoV-2 Cell Entry Depends on ACE2 and TMPRSS2 and Is Blocked by a Clinically Proven Protease Inhibitor. Cell 2020, 181 (2), 271-280 e8.

6. Letko, M.; Marzi, A.; Munster, V., Functional assessment of cell entry and receptor usage for SARS-CoV-2 and other lineage B betacoronaviruses. Nat Microbiol 2020, 5 (4), 562569.

7. $\quad$ Raj, V. S.; Mou, H.; Smits, S. L.; Dekkers, D. H. W.; Müller, M. A.; Dijkman, R.; Muth, D.; Demmers, J. A. A.; Zaki, A.; Fouchier, R. A. M.; Thiel, V.; Drosten, C.; Rottier, P. J. M.; Osterhaus, A. D. M. E.; Bosch, B. J.; Haagmans, B. L., Dipeptidyl peptidase 4 is a functional receptor for the emerging human coronavirus-EMC. Nature 2013, 495 (7440), 251-254.

8. Millet, J. K.; Whittaker, G. R., Host cell proteases: Critical determinants of coronavirus tropism and pathogenesis. Virus Research 2015, 202, 120-134.

9. Mingo, R. M.; Simmons, J. A.; Shoemaker, C. J.; Nelson, E. A.; Schornberg, K. L.; D'Souza, R. S.; Casanova, J. E.; White, J. M., Ebola virus and severe acute respiratory syndrome coronavirus display late cell entry kinetics: evidence that transport to NPC1+ endolysosomes is a rate-defining step. J Virol 2015, 89 (5), 2931-43.

10. Huang, I. C.; Bosch, B. J.; Li, F.; Li, W.; Lee, K. H.; Ghiran, S.; Vasilieva, N.; Dermody, T. S.; Harrison, S. C.; Dormitzer, P. R.; Farzan, M.; Rottier, P. J. M.; Choe, H., SARS Coronavirus, but Not Human Coronavirus NL63, Utilizes Cathepsin L to Infect ACE2-expressing Cells. Journal of Biological Chemistry 2006, 281 (6), 3198-3203.

11. Simmons, G.; Gosalia, D. N.; Rennekamp, A. J.; Reeves, J. D.; Diamond, S. L.; Bates, P., Inhibitors of cathepsin $L$ prevent severe acute respiratory syndrome coronavirus entry. $P$ Natl Acad Sci USA 2005, 102 (33), 11876.

12. Matsuyama, S.; Nagata, N.; Shirato, K.; Kawase, M.; Takeda, M.; Taguchi, F., Efficient Activation of the Severe Acute Respiratory Syndrome Coronavirus Spike Protein by the Transmembrane Protease TMPRSS2. Journal of Virology 2010, 84 (24), 12658.

13. Shulla, A.; Heald-Sargent, T.; Subramanya, G.; Zhao, J.; Perlman, S.; Gallagher, T., A transmembrane serine protease is linked to the severe acute respiratory syndrome coronavirus receptor and activates virus entry. Journal of virology 2011, 85 (2), 873-882.

14. Shirato, K.; Kawase, M.; Matsuyama, S., Middle East Respiratory Syndrome Coronavirus Infection Mediated by the Transmembrane Serine Protease TMPRSS2. Journal of Virology 2013, 87 (23), 12552.

15. Belouzard, S.; Chu, V. C.; Whittaker, G. R., Activation of the SARS coronavirus spike protein via sequential proteolytic cleavage at two distinct sites. Proceedings of the National Academy of Sciences 2009, 106 (14), 5871.

16. Qing, E.; Hantak, M. P.; Galpalli, G. G.; Gallagher, T., Evaluating MERS-CoV entry pathways. In MERS Coronavirus, Springer: 2020; pp 9-20.

17. Jaimes, J. A.; Millet, J. K.; Whittaker, G. R., Proteolytic cleavage of the SARS-CoV-2 spike protein and the role of the novel S1/S2 site. Iscience 2020, 101212.

18. Bestle, D.; Heindl, M. R.; Limburg, H.; Pilgram, O.; Moulton, H.; Stein, D. A.; Hardes, K.; Eickmann, M.; Dolnik, O.; Rohde, C., TMPRSS2 and furin are both essential for proteolytic activation of SARS-CoV-2 in human airway cells. Life science alliance 2020, 3 (9).

19. Johnson, B. A.; Xie, X.; Kalveram, B.; Lokugamage, K. G.; Muruato, A.; Zou, J.; Zhang, X.; Juelich, T.; Smith, J. K.; Zhang, L.; Bopp, N.; Schindewolf, C.; Vu, M.; Vanderheiden, A.; Swetnam, D.; Plante, J. A.; Aguilar, P.; Plante, K. S.; Lee, B.; Weaver, S. C.; Suthar, M. S.; Routh, A. L.; Ren, P.; Ku, Z.; An, Z.; Debbink, K.; Shi, P. Y.; Freiberg, A. N.; Menachery, V. D., Furin Cleavage Site Is Key to SARS-CoV-2 Pathogenesis. bioRxiv 2020, 2020.08.26.268854. 
20. Shang, J.; Wan, Y.; Luo, C.; Ye, G.; Geng, Q.; Auerbach, A.; Li, F., Cell entry mechanisms of SARS-CoV-2. Proc Natl Acad Sci U S A 2020, 117 (21), 11727-11734.

21. Oguntuyo, K. Y.; Stevens, C. S.; Siddiquey, M. N. A.; Schilke, R. M.; Woolard, M. D.; Zhang, H.; Acklin, J. A.; Ikegame, S.; Huang, C.-T.; Lim, J. K.; Cross, R. W.; Geisbert, T. W.; Ivanov, S. S.; Kamil, J. P.; Lee, B., In plain sight: the role of alpha-1-antitrypsin in COVID-19 pathogenesis and therapeutics. bioRxiv 2020, 2020.08.14.248880.

22. Laporte, M.; Raeymaekers, V.; Van Berwaer, R.; Vandeput, J.; Marchand-Casas, I.; Thibaut, H.-J.; Van Looveren, D.; Martens, K.; Hoffmann, M.; Maes, P.; Pöhlmann, S.; Naesens, L.; Stevaert, A., The SARS-CoV-2 and other human coronavirus spike proteins are fine-tuned towards temperature and proteases of the human airways. PLOS Pathogens 2021, 17 (4), e1009500.

23. Brecher, M.; Schornberg, K. L.; Delos, S. E.; Fusco, M. L.; Saphire, E. O.; White, J. M., Cathepsin cleavage potentiates the Ebola virus glycoprotein to undergo a subsequent fusionrelevant conformational change. J Virol 2012, 86 (1), 364-72.

24. Carette, J. E.; Raaben, M.; Wong, A. C.; Herbert, A. S.; Obernosterer, G.; Mulherkar, N.; Kuehne, A. I.; Kranzusch, P. J.; Griffin, A. M.; Ruthel, G.; Dal Cin, P.; Dye, J. M.; Whelan, S. P.; Chandran, K.; Brummelkamp, T. R., Ebola virus entry requires the cholesterol transporter Niemann-Pick C1. Nature 2011, 477 (7364), 340-3.

25. Koch, J.; Uckeley, Z. M.; Doldan, P.; Stanifer, M.; Boulant, S.; Lozach, P.-Y., Host Cell Proteases Drive Early or Late SARS-CoV-2 Penetration. bioRxiv 2020, 2020.12.22.423906.

26. Haldar, S.; Okamoto, K.; Dunning, R. A.; Kasson, P. M., Precise triggering and chemical control of single-virus fusion within endosomes. Journal of Virology 2020, JVI.01982-20.

27. Chao, L. H.; Klein, D. E.; Schmidt, A. G.; Pena, J. M.; Harrison, S. C., Sequential conformational rearrangements in flavivirus membrane fusion. Elife 2014, 3, e04389.

28. Costello, D. A.; Millet, J. K.; Hsia, C. Y.; Whittaker, G. R.; Daniel, S., Single particle assay of coronavirus membrane fusion with proteinaceous receptor-embedded supported bilayers. Biomaterials 2013, 34 (32), 7895-904.

29. van der Borg, G.; Braddock, S.; Blijleven, J. S.; van Oijen, A. M.; Roos, W. H., Singleparticle fusion of influenza viruses reveals complex interactions with target membranes. Journal of Physics: Condensed Matter 2018, 30 (20), 204005.

30. Floyd, D.; Ragains, J. R.; Skehel, J. J.; Harrison, S. C.; van Oijen, A. M., Single-particle kinetics of influenza virus membrane fusion. Proc Natl Acad Sci U S A 2008, 105 (40), 15382-7. 31. Liu, K. N.; Boxer, S. G., Single-virus content mixing assay reveals cholesterol-enhanced influenza membrane fusion efficiency. bioRxiv 2021, 2021.04.26.441491.

32. Ivanovic, T.; Choi, J. L.; Whelan, S. P.; van Oijen, A. M.; Harrison, S. C., Influenza-virus membrane fusion by cooperative fold-back of stochastically induced hemagglutinin intermediates. Elife 2013, 2, e00333.

33. Yang, S. T.; Kreutzberger, A. J. B.; Kiessling, V.; Ganser-Pornillos, B. K.; White, J. M.; Tamm, L. K., HIV virions sense plasma membrane heterogeneity for cell entry. Sci Adv 2017, 3 (6), e1700338.

34. Goronzy, I. N.; Rawle, R. J.; Boxer, S. G.; Kasson, P. M., Cholesterol enhances influenza binding avidity by controlling nanoscale receptor clustering. Chemical Science 2018.

35. Simmons, G.; Bertram, S.; Glowacka, I.; Steffen, I.; Chaipan, C.; Agudelo, J.; Lu, K.; Rennekamp, A. J.; Hofmann, H.; Bates, P.; Pöhlmann, S., Different host cell proteases activate the SARS-coronavirus spike-protein for cell-cell and virus-cell fusion. Virology 2011, 413 (2), 265-274.

36. Zawada, K. E.; Okamoto, K.; Kasson, P. M., Influenza Hemifusion Phenotype Depends on Membrane Context: Differences in Cell-Cell and Virus-Cell Fusion. J Mol Biol 2018, 430 (5), 594-601. 
37. Follis, K. E.; York, J.; Nunberg, J. H., Furin cleavage of the SARS coronavirus spike glycoprotein enhances cell-cell fusion but does not affect virion entry. Virology 2006, 350 (2), 358-369.

38. Floyd, D. L.; Harrison, S. C.; van Oijen, A. M., Analysis of kinetic intermediates in singleparticle dwell-time distributions. Biophys J 2010, 99 (2), 360-6.

39. Wessels, L.; Elting, M. W.; Scimeca, D.; Weninger, K., Rapid membrane fusion of individual virus particles with supported lipid bilayers. Biophys $J$ 2007, 93 (2), 526-38.

40. Rawle, R. J.; Webster, E. R.; Jelen, M.; Kasson, P. M.; Boxer, S. G., pH dependence of Zika membrane fusion kinetics reveals an off-pathway state. ACS Central Science 2018.

41. Ward, A. E.; Kiessling, V.; Pornillos, O.; White, J. M.; Ganser-Pornillos, B. K.; Tamm, L. K., HIV-cell membrane fusion intermediates are restricted by Serincs as revealed by cryoelectron and TIRF microscopy. Journal of Biological Chemistry 2020, 295 (45), 15183-15195.

42. Rawle, R. J.; Villamil Giraldo, A. M.; Boxer, S. G.; Kasson, P. M., Detecting and Controlling Dye Effects in Single-Virus Fusion Experiments. Biophys J 2019, 117 (3), 445-452.

43. Scott, R. E.; Perkins, R. G.; Zschunke, M. A.; Hoerl, B. J.; Maercklein, P. B., Plasma membrane vesiculation in 3T3 and SV3T3 cells. I. Morphological and biochemical characterization. Journal of Cell Science 1979, 35 (1), 229-243.

44. Villamil Giraldo, A. M.; Kasson, P., Bilayer-Coated Nanoparticles Reveal How Influenza Viral Entry Depends on Membrane Deformability but Not Curvature. Journal of Physical Chemistry Letters 2020, 11, 7190-7196.

45. Otterstrom, J. J.; Brandenburg, B.; Koldijk, M. H.; Juraszek, J.; Tang, C.; Mashaghi, S.; Kwaks, T.; Goudsmit, J.; Vogels, R.; Friesen, R. H.; van Oijen, A. M., Relating influenza virus membrane fusion kinetics to stoichiometry of neutralizing antibodies at the single-particle level. Proc Natl Acad Sci U S A 2014, 111 (48), E5143-8.

46. Danieli, T.; Pelletier, S. L.; Henis, Y. I.; White, J. M., Membrane fusion mediated by the influenza virus hemagglutinin requires the concerted action of at least three hemagglutinin trimers. J Cell Biol 1996, 133 (3), 559-69.

47. Kou, S. C.; Cherayil, B. J.; Min, W.; English, B. P.; Xie, X. S., Single-molecule MichaelisMenten equations. J Phys Chem B 2005, 109 (41), 19068-81.

48. Shaevitz, J. W.; Block, S. M.; Schnitzer, M. J., Statistical kinetics of macromolecular dynamics. Biophys J 2005, 89 (4), 2277-85.

49. Moffitt, J. R.; Bustamante, C., Extracting signal from noise: kinetic mechanisms from a Michaelis-Menten-like expression for enzymatic fluctuations. FEBS J 2014, 281 (2), 498-517.

50. Yasuoka, S.; Ohnishi, T.; Kawano, S.; Tsuchihashi, S.; Ogawara, M.; Masuda, K.; Yamaoka, K.; Takahashi, M.; Sano, T., Purification, characterization, and localization of a novel trypsin-like protease found in the human airway. American Journal of Respiratory Cell and Molecular Biology 1997, 16 (3), 300-308.

51. Kido, H.; Yokogoshi, Y.; Sakai, K.; Tashiro, M.; Kishino, Y.; Fukutomi, A.; Katunuma, N., Isolation and characterization of a novel trypsin-like protease found in rat bronchiolar epithelial Clara cells. A possible activator of the viral fusion glycoprotein. Journal of Biological Chemistry 1992, 267 (19), 13573-13579.

52. Menou, A.; Duitman, J.; Flajolet, P.; Sallenave, J.-M.; Mailleux, A. A.; Crestani, B., Human airway trypsin-like protease, a serine protease involved in respiratory diseases. American Journal of Physiology-Lung Cellular and Molecular Physiology 2017, 312 (5), L657L668.

53. Schornberg, K.; Matsuyama, S.; Kabsch, K.; Delos, S.; Bouton, A.; White, J., Role of endosomal cathepsins in entry mediated by the Ebola virus glycoprotein. Journal of Virology 2006, 80 (8), 4174-4178.

54. Gunst, J. D.; Staerke, N. B.; Pahus, M. H.; Kristensen, L. H.; Bodilsen, J.; Lohse, N.; Dalgaard, L. S.; Brønnum, D.; Fröbert, O.; Hønge, B.; Johansen, I. S.; Monrad, I.; Erikstrup, C.; Rosendal, R.; Vilstrup, E.; Mariager, T.; Bove, D. G.; Offersen, R.; Shakar, S.; Cajander, S.; 
Jørgensen, N. P.; Sritharan, S. S.; Breining, P.; Jespersen, S.; Mortensen, K. L.; Jensen, M. L.; Kolte, L.; Frattari, G. S.; Larsen, C. S.; Storgaard, M.; Nielsen, L. P.; Tolstrup, M.; Sædder, E. A.; Østergaard, L. J.; Ngo, H. T. T.; Jensen, M. H.; Højen, J. F.; Kjolby, M.; Søgaard, O. S., Efficacy of the TMPRSS2 inhibitor camostat mesilate in patients hospitalized with Covid-19-a double-blind randomized controlled trial. EClinicalMedicine.

55. Hoffmann, M.; Schroeder, S.; Kleine-Weber, H.; Muller, M. A.; Drosten, C.; Pohlmann, S., Nafamostat Mesylate Blocks Activation of SARS-CoV-2: New Treatment Option for COVID19. Antimicrob Agents Chemother 2020, 64 (6).

56. Hoffmann, M.; Hofmann-Winkler, H.; Smith, J. C.; Krüger, N.; Arora, P.; Sørensen, L. K.; Søgaard, O. S.; Hasselstrøm, J. B.; Winkler, M.; Hempel, T.; Raich, L.; Olsson, S.; Danov, O.; Jonigk, D.; Yamazoe, T.; Yamatsuta, K.; Mizuno, H.; Ludwig, S.; Noé, F.; Kjolby, M.; Braun, A.; Sheltzer, J. M.; Pöhlmann, S., Camostat mesylate inhibits SARS-CoV-2 activation by TMPRSS2-related proteases and its metabolite GBPA exerts antiviral activity. EBioMedicine 2021, 65. 